\title{
Organisational Training Perspectives in a Changing South Africa
}

\author{
F W Struwig and $\mathbf{E} \mathbf{E}$ Smith \\ Department of Business Management, Vista University, Port Elizabeth
}

\section{J L Venter}

Institute for Statistical Consultation \& Methodology, University of Port Elizabeth

\begin{abstract}
This article focuses on organisational training perspectives within a changing South African context. To achieve the aim of this research project, a literature study, including an Internet-based search, and empirical research were undertaken. During the empirical research, a self-administered questionnaire was sent to 365 training practitioners in order to investigate various training perspectives and its relationship with organisational change. Five null hypotheses are tested to investigate the relationship between training and change variables. The traditional role of training has become obsolete, because of organisational change. Training should be placed at the centre of human resources planning programmes and the strategic plans of the organisation. It is emphasised that actions should be taken to ensure that training programmes affect change and that trainees involved in the change process are effectively managed.
\end{abstract}

JEL M51, 53

\section{INTRODUCTION}

The important role of training in an organisation is highlighted by Eagar (1996: 61) and Stamelman (2000: 34) who contend that there is a growing need to develop an adequate quantity and quality of talent in contemporary organisations. The challenge of achieving higher productivity and skills levels, therefore, places increasing demands on the capacity to educate and train large numbers of people in South Africa. This can, however, not be achieved by a one or two-day course or workshop. Instead, training should be viewed as a planned process of bringing about fundamental change in the organisation and its employees (Ogbonna, 2002: 1). 
This article focuses on important directions, trends and perspectives of training in South African organisations and its facilitating role in managing organisational change. Research literature on the topic of training appears to be quite extensive (see the contributions of Davis \& Davis, 2001; Hardingham, 1997; Honold, 2000 and Kempl \& Pace, 2001). Adonisi (1991: 27) maintains that "the rapidly changing socio-economic and political climate in South Africa poses formidable challenges to management in general and human resources managers in particular." What is of importance is the challenge facing organisational leaders to create self-renewing organisations that will provide the capacity to handle the tide of change. Erasmus and Van Dyk (1996: vxii) concur that one of the crucial challenges facing South African organisations is how to manage change. According to Bowin and Harvey (2001: 179), employee training will become increasingly important in the new millennium, because of the pressures to reduce costs, increase productivity and to accelerate change. Winning organisations will be those that respond quickly to changing conditions and the critical issue of training related issues. Training should be viewed as a process which begins with the orientation of the new employee and continues throughout an employee's career. Teke (1997: 24) further emphasises the important role of training in empowering the workforce to be creative and innovative in meaningful business activities. Manning (1996: 10) also stresses that of all tasks facing contemporary organisations, training and development of people is the most crucial - there is no other way to productivity, profitability or survival in the new business arena.

In this article, a theoretical overview of training will first be given. Training trends and issues, the development of a training philosophy and policy, strategic training implications and the role of training in managing organisational change will be highlighted. Thereafter, the hypotheses and research method will be outlined. Lastly, the results and main conclusions and recommendations will be dealt with.

\section{TRAINING PERSPECTIVES: A THEORETICAL OVERVIEW}

\subsection{Training trends and issues}

Carroll (1998: 1) stresses that it is important to understand the changing picture of the world in which organisations operate, as this provides the context in which to consider the future of training management. Buckley and Caple (1992: 229), however, argue that many of the ideas and beliefs about training "represent a Utopian world of training" which they cannot imagine ever being realised. Despite this notion, this section will provide an overview of contemporary trends and issues in training. 
The Open Learning Technology Corporation (1995: 1) emphasises that there has been a renewed focus of attention on the role of training in equipping people for productive and satisfying careers. Elements of training reform include: encouraging more people to participate in training; joint school-industry training programmes, increasing the number of and access to workplace entry level training and improving the performance of the vocational training system. Jarvis (2002: 1) further stresses the freedom of movement through common vocational qualifications across occupations and professions and the right to receive training throughout working life. Berggren (2000: 3) indicates the shift in orientation from viewing training as a cost centre and "one-size-fits-all" training programmes to view training as a source of competitive advantage and tailor-made training programmes. Masie (2002:1) outlines the following three general trends in corporate training: training will become e-learning (learning with technology); intranet learning (learning within the organisation by means of an internal e-business and from everyday work) and knowledge management. Human (1991: 199) alleges that the presence of a learning and training culture in an organisation is not indicated by the size of its training budget, but woven into the value and belief system of organisational members. Table 1 provides a summary (as suggested by American Society for Training and Development, 2000; Lippitt, 1997 and Setaro, 2002) of the most important directions and trends in training.

\section{Table 1 Trends in corporate training}

\begin{tabular}{|c|c|}
\hline Author & Most important training trends \\
\hline \multirow{10}{*}{$\begin{array}{l}\text { American } \\
\text { Society for } \\
\text { Training and } \\
\text { Development } \\
(2000)\end{array}$} & 1 Increased skill requirements because of change \\
\hline & 2 A more educated and diverse workforce \\
\hline & 3 Corporate restructuring and its affect on employee morale \\
\hline & 4 Change in size and composition of training departments \\
\hline & 5 Advances in technology will revolutionise training delivery \\
\hline & 6 Creating supporting networks of providing training services \\
\hline & 7 More focus on performance improvement \\
\hline & 8 Re-examining of training's role in the organisation \\
\hline & 9 Organisations will transform into learning organisations \\
\hline & 10 Increased emphasis on human performance management \\
\hline \multirow[t]{7}{*}{ Lippitt (1997) } & 1 Customisation of training programmes \\
\hline & 2 Training should address organisation-wide issues \\
\hline & 3 Multi-skilling or cross training \\
\hline & 4 Development of activities for individual career building \\
\hline & 5 Large scale change efforts involving all stakeholders \\
\hline & 6 Computer-based training (e-learning) \\
\hline & 7 Training to be conducted at multiple sites \\
\hline
\end{tabular}


Table 1 continued

\begin{tabular}{|l|ll|}
\hline \multicolumn{1}{|c|}{ Author } & \multicolumn{1}{c|}{ Most important training trends } \\
\hline Lippitt (1997) & 8 & Training on-the-job by means of teams \\
& 9 & Top management involvement in training \\
\hline \multirow{4}{*}{ Setaro (2002) } & 1 & Shift from classroom to computer-based instruction \\
\cline { 2 - 3 } & 2 & Application of synchronous training models \\
\cline { 2 - 3 } & 3 & Increased used of threaded discussions to facilitate training \\
\cline { 2 - 3 } & 4 & Decline demand for "canned" training programmes \\
\cline { 2 - 3 } & 5 & Complex training materials - use external training \\
\hline & 6 & Development of partnerships/agreements in e-learning \\
\cline { 2 - 3 } & 7 & Cooperation between tertiary sector \& e-learning providers \\
\hline & 8 & Content/presentation of training incorporating new findings \\
\cline { 2 - 3 } & 9 & $\begin{array}{l}\text { Relying on organisations providing comprehensive } \\
\text { training management systems }\end{array}$ \\
\cline { 2 - 3 } & 10 & $\begin{array}{l}\text { Shift from private ownership of learning towards one of } \\
\text { public ownership }\end{array}$ \\
\hline
\end{tabular}

In analysing the above-mentioned trends, it appears that training should position itself as a strategic tool. Developers of training programmes should therefore take note of these directions in training when designing training programmes in order to ensure its effectiveness. The different approaches to training are outlined in Table 2 below.

Table 2 Modern approaches to training

\begin{tabular}{|c|l|}
\hline Approach & \multicolumn{1}{c|}{ Characteristics } \\
\hline Fragmented & TRAINING IS: \\
& * a cost not an investment \\
& * not linked to organisational goals \\
& * perceived as a luxury \\
& * directive oriented \\
& * taking place in the training department only \\
& * primarily knowledge-based courses \\
\hline Formalised & TRAINING IS: \\
& * systematic (part of planned career development). \\
& * linked to human resources needs \\
& * linked to appraisal/individual needs \\
\cline { 2 - 3 } & * knowledge-based courses and focussing on skills \\
& * linked to career development \\
& * carried out by trainers and line managers \\
& * linked to the job by means of course work \\
& * a continuous learning process \\
\hline
\end{tabular}




\section{Table 2 continued}

\begin{tabular}{|l|l|}
\hline \multicolumn{1}{|c|}{ Approach } & \multicolumn{1}{c|}{ Characteristics } \\
Formalised & * essential for organisational survival \\
& * a competitive weapon \\
& * linked to organisational strategy and individual goals \\
& $*$ on-the-job and specialist courses \\
\hline Focussed & TRAINING IS: \\
& * self-selected \\
& * usually non-directive \\
& $*$ line manager's responsibility \\
\hline
\end{tabular}

Source: Osbaldeston and Barham (1992: 22)

The focussed approach depicted in Table 2 views training and continuous learning by individuals as a necessity for survival and fosters the flexibility needed to keep pace with change in a competitive environment. Baird, Schneier and Laird (1983: 286) attest to the fact that "employees will see training as a right rather than an amusing and interesting sideline... this will produce a maturity and professionalism in training never realised in the past."

\subsection{Training philosophy and policy issues}

Erasmus and Van Dyk (1996: 44) view a training philosophy as management's attitude or perception of the importance of its human resources potential in the organisation. Van Dyk, Nel, Loedolff and Haasbroek (1997: 161) assert that the following assumptions could serve as a basis for a training and development philosophy in the South African context: an employee should not be employed and trained in order to acquire skills and experience and then leave the organisation; an employee must be selected for training, based on the belief that he or she will become a lifelong member; an employee is an asset which appreciates in value and an organisation has a social responsibility to invest in employees by means of training.

The training philosophy states the organisation's intent in utilising its human resources potential and should be regarded as the starting point in the training process (Gomez-Mejia, Balkin \& Cardy, 2001: 259). It appears, however, that this is the most neglected aspect of training management. An organisation's training philosophy is manifested through its training policy which provides a guideline for the conduct of affairs with regard to training. These training philosophies and policies could be justified in terms of various management theories. These theories emphasise the important role of people and investment in human capital. Training of employees could be seen as such an investment in human capital. The human relations approach views employees as human beings 
with certain rights and not as machines (Smit \& Cronje, 1997: 43). The systems approach emphasises human resources inputs which goes through a transformation/change process to deliver effective and productive employees (Hellriegel \& Slocum, 1996: 55). According to Hammer and Champy (1993: 12) people is the key driving force in affecting drastic organisational change and human resources programmes should be closely coordinated with the reengineering effort. Table 3 highlights some broad policy options of a strategic nature, which reflect the training aspect of the human resources development policy environment in which contemporary organisations operate. It provides an outline of possible training policy options for South Africa.

Managers and training practitioners must therefore ensure that the training policy of the organisation is in alignment with these broad and general policy options mentioned in Table 3. From what has been discussed with regard to training policies, it should be clear that the setting of a training policy is of vital importance to organisations that wish to implement successful training. Only when there is a thorough understanding of the function of training throughout the organisation, can training play an effective role.

Table 3 Possible training policy options for South Africa

\begin{tabular}{|c|l|}
\hline $\begin{array}{c}\text { Policy } \\
\text { option }\end{array}$ & \multicolumn{1}{|c|}{ Description } \\
\hline 1 & $\begin{array}{l}\text { Align human resources development policies with economic and } \\
\text { social development policies. }\end{array}$ \\
\hline 2 & $\begin{array}{l}\text { Introduce measures to turn around the current enrolment ratios of } \\
\text { universities to career institutions. }\end{array}$ \\
\hline 3 & $\begin{array}{l}\text { Establish strategic partnerships between the state and } \\
\text { organisations that are based on trust, co-determination and } \\
\text { sharing of responsibilities. }\end{array}$ \\
\hline 4 & $\begin{array}{l}\text { Institute a world-class education system that will instill a culture } \\
\text { of learning and respond to the needs of the economy. }\end{array}$ \\
\hline 5 & Revitalise the current vocational education and training system. \\
\hline 6 & $\begin{array}{l}\text { Target the informal sector as an area of intervention by using } \\
\text { training as an instrument to transfer knowledge, skills and } \\
\text { attitudes. }\end{array}$ \\
\hline 7 & $\begin{array}{l}\text { Training provided to the unemployed should form an integral part } \\
\text { of active labour market policies. }\end{array}$ \\
\hline
\end{tabular}

Source: Adapted from Van Dyk et al. (1997: 27)

Training activities should not be viewed as a separate specialised function, but rather as an integral component of management action. All sections of the 
organisation should be given the opportunity to review activities in the context of a training policy.

\subsection{Strategic training implications}

Nickols (2000: 4) criticises the traditional approach to training in which the future is ignored and the main focus is only on past performance, data and competencies. To reorientate training to a strategic approach (which is consistent with human resources' grand strategy), training practitioners must become familiar with the organisation's strategic plans. Corporate Training Consultants (2000: 2) alleges that the strategic management process optimally positions the organisation in the competitive environment, to ensure both the survival and growth of the organisation. The need to integrate human resources planning (and therefore training as well) into the organisation's strategic planning process has been advocated by several authors (see for example, Buckley \& Caple, 1992 and Erasmus \& Van Dyk, 1996). Budd (1996: 5) contends that the success of training efforts is experienced if training is not only managed professionally, but also linked to the organisation's mission and goals.

According to Nickols (2000: 4), training has several strategic roles in the implementation of a human resources strategy. It is a potential tool for creating a supply of talent within the organisation. Training also serves as a tool for equipping individuals with knowledge, skills and attitudes needed to implement the organisation's strategy. A further strategic role of training is that it stimulates conditions which may be experienced as the organisation implements a new strategy in a changing environment. Training also provides individuals with the necessary skills to think strategically.

It should be clear that training is a powerful tool in the implementation of a human resources strategy. Gerber, Nel, Van Dyk, Haasbroek, Schultz, Sono and Werner (2001: 557) emphasise the following main strategic benefits of integrating strategic planning and human resources and training management: improved understanding of the implications of strategic organisational planning for human resources; pro active recruitment of required and experienced human resources; improved human resources development activities; improved analysis and control of costs related to human resources. The traditional and functional role of training, therefore needs to be revised in a changing environment. Human resources, in the context of strategic human resources development, are therefore seen as a vital factor in business planning and survival. This implies moving human resources development from a series of fragmented activities to a situation where training is systematically linked to the master or strategic plan of the organisation. 


\subsection{The role of training in managing organisational change}

Dawson (1994: 176) asserts that "training can be used as a vehicle for informing employees of the nature, consequences and opportunities afforded by change." Blunt and Jones (1992: 311) believe that the upgrading of managerial capabilities is a continuing need in situations of rapid change. According to Joyce and Woods (1996: 255) there is a need to develop strategic managers. Much of the training of strategic managers has however been limited in its applicability to contemporary conditions. Thompson and Mabey (1994: 218) argue that there are two ways in which training (a component of human resources development) can influence the management of organisational change. The first role is to respond to externally driven changes at organisational level (shifts in strategic action). The second role is an internal one - developing and shaping the appropriate competencies, practices and attitudes which will assist the organisation to deliver its products and services.

Bowman and Jarrett (1996: 220) and Thompson (1995: 172) also indicate the use of training as a strategy to facilitate the transition of change. Educating and training people for change beforehand can assist in understanding why the change is necessary. For training to serve as a vehicle for change, change agents must ensure that training is used for the correct purposes. The crucial role of training in the stage of planning the proposed change is emphasised by Burnes (1996: 332) who highlights that training is the key element in any change project. The result of training can be the development of new skills, that people are left with the ability to pursue continuous improvement or that they are made aware of the need for change. Besides the key role of training in planning the change, Brill and Worth (1997: 62) indicate the role of training in initiating the change process. Through a seminar or workshop, people can examine personal needs, levels of morale and leadership styles. This new insight and perspective can help people to disconnect from old habits and to open up to initiating change in the organisation.

According to Kanter, Stein and Jick (1992: 510), the use of training during the implementation of change is also important. This means that people need to be reoriented, redirected or engaged in new activities which require new knowledge, motivation or skills. Tobin (1993: 198), on the other hand, advocates the creation of a virtual training organisation and states that the "traditional training organisation", if it is to assist with organisational change, needs to transform itself. The traditional training organisation focuses on the development of individual skills, does not participate in the organisation's planning efforts and is not a change agent.

Several specific organisational characteristics serve as variables in this study. These include: size of the organisation as measured by the number of 
employees, the existence of a fully developed training department in the organisation and type of environment in which the organisation operates. From the aforementioned, the following three null hypotheses are formulated:

$\mathrm{H}_{1} \quad$ The number of employees (size of organisation) is not related to the role of training in managing organisational change.

$\mathrm{HO}_{2}$ There is no relationship between an organisation which has a fully developed training department and the role of training in managing organisational change.

$\mathrm{H}_{3}$ There is no relationship between the environment in which an organisation operates and the role of training in managing organisational change.

The main objective of this article is to investigate various training perspectives in a changing South Africa. A more specific focal point is to analyse the role of training in managing organisational change. In analysing the literature on change management, three topics continually came to the forefront: organisational development (see for example Larwood, 1984: 450 and Robbins, 1996: 736), the learning organisation (Dawson, 1992: 209 and Hendry, Johnson \& Newton, 1994: 230) and transformational leadership (Bowditch \& Buono, 1994: 235 and Hersey, Blanchard \& Johnson, 1996: 521). It could, therefore, be said that organisational development, the learning organisation and transformational leadership, form the architecture or building blocks of the interaction between training and change. These building blocks are used as the change variables in this project. An in-depth discussion of these topics, however, falls beyond the scope of this article, but are empirically tested. It should be mentioned that this article and its results forms part of a bigger project. Based on this reasoning and background, the following two null hypotheses are formulated:

$\mathrm{H}_{4}$ There is no relationship between the facilitating role of training and the application of organisational change processes.

$\mathrm{H}_{5}$ There is no relationship between the role of training and managing organisational change.

Training must therefore not only be seen as a functional area in the organisation, but needs to possess the capabilities necessary to help change the organisation. 


\section{RESEARCH METHOD}

\subsection{Sample selection}

For the purpose of this research project, the target population was chosen from South African organisations. All organisations with a training department or section, headed by a training practitioner or director, could therefore be regarded as the target population. The sample selected for this project was drawn by the South African Board for Personnel Practices (SABPP). It would be impractical to include all organisations in South Africa. The database provided, included all registered training practitioners with the SABPP (probability sampling). A total sample size of 365 was used.

\subsection{Questionnaire design}

Based on the size of the sample (365), a mail survey by means of questionnaires was best suited to this project. The questionnaire consists out of three sections:

- Section A deals with organisational change variables. Three organisational change constructs/factors are tested, namely organisational development (10 variables, the learning organisation (15 variables) and transformational leadership (15 variables).

- Section B covers various perspectives on training. Two constructs are tested, namely the facilitating role of training in the application of organisational change processes (11 variables) and the role of training in managing organisational change (14 variables).

- Section C provides classification data (demographic characteristics) about respondents.

The type of ordinal scale used in Section A and B of the questionnaire is a fivepoint Likert-type scale. Section $\mathrm{C}$ of the questionnaire contains a nominal scale of measurement in which respondents were asked to provide some classification data about themselves and their organisations.

A factor analysis was also conducted. The BMDP statistical software package (Programme 4M) was used to perform the factor analysis. Factors were extracted using Principle Component Analysis with Direct Quartimin Oblique rotation to allow for intercorrelations between factors. To confirm that all items load on a single factor and to explain the percentage of variance, Cronbach's alpha was calculated, as indicated in Table 4. 
Table 4 Cronbach's alpha for section A and B of the questionnaire

\begin{tabular}{|c|c|l|c|c|}
\hline Section & Variables & \multicolumn{1}{|c|}{ Factor } & $\begin{array}{c}\text { Cronbach's } \\
\text { alpha }\end{array}$ & $\begin{array}{c}\text { \% of } \\
\text { variance }\end{array}$ \\
\hline \multirow{2}{*}{$\mathrm{A}$} & $1-10$ & $\begin{array}{l}\text { Organisational } \\
\text { development (A1) }\end{array}$ & 0.92 & 57.6 \\
\cline { 2 - 5 } & $11-25$ & $\begin{array}{l}\text { Learning organisation } \\
\text { (A2) }\end{array}$ & 0.95 & 59.5 \\
\cline { 2 - 5 } & $26-40$ & $\begin{array}{l}\text { Transformational } \\
\text { leadership (A3) }\end{array}$ & 0.95 & 60.3 \\
\hline \multirow{2}{*}{$\mathrm{B}$} & $1-11$ & $\begin{array}{l}\text { The facilitating role of } \\
\text { training in the application } \\
\text { of the building blocks of } \\
\text { change (B1) }\end{array}$ & 0.94 & 62.0 \\
\cline { 2 - 5 } & $12-25$ & $\begin{array}{l}\text { Role of training in } \\
\text { managing organisational } \\
\text { change (B2) }\end{array}$ & 0.92 & 49.9 \\
\hline
\end{tabular}

Table 4 highlights the internal reliability of the measuring instrument. Cronbach's alpha should be above 0.7 to indicate internal reliability. It can therefore be concluded that all factors are internally reliable (Cronbach's alpha > 0.7). The percentage of variance refers to the percentage of variance of the items constituting each factor, as explained by each factor. The highest percentage of variance is for the facilitating role of training in the application of organisational change processes and explains 62.0 per cent of the variance of the items or variables constituting this factor. The face validity of the measuring instrument was ensured by means of consulting secondary sources in order to incorporate theoretical aspects and a pretest of the questionnaire.

\subsection{Pilot study}

Due to the fact that the questionnaire had never been used before in any research project, it was issued to 40 organisations (convenient sample) in the Port Elizabeth-Uitenhage area for pilot testing. Wherever possible, it was issued to human resources managers and training specialists to complete. The questionnaire was also given to academics in the field of management, training, industrial psychology and statistics in order to identify any problem areas, to obtain suggestions for improvement and to ensure face validity. 


\subsection{Data collection}

A total of 365 covering letters, questionnaires and return-paid envelopes were posted and a reminder postcard was sent a week later. Various measures were implemented to deal with the aspect of low response rates associated with mail surveys. The response rate of this survey is 54,25 per cent (198 questionnaires from a possible 365 included in the sample). The effective response rate (usable questionnaires) is 49,86 per cent (182 responses from a possible 365 ).

\subsection{Data processing and analysis}

Questionnaires which were received from respondents were inspected, edited, coded and transferred for storage. The coding of questionnaires was carried out by the researcher in conjunction with the statistician responsible for assisting with the analysis of data. The following are examples of the techniques used during the data analysis stage of the research project: descriptive statistics, factor analysis, analysis of variance and correlation coefficients.

\section{SURVEY RESULTS}

\subsection{Descriptive statistics}

Section B of the questionnaire concentrates on various perspectives of training, and more specifically, the role of training in managing organisational change. The variables tested whether training is important to affect change in the organisation. A summary of the descriptive statistics for these variables reveals that all the mean values lie between point three (neutral) and point four (agree slightly) on the five-point Likert scale. The median values indicate that most respondents agree slightly (point four on the scale) with the variables in this part of the questionnaire. The first quartile (Q1) shows that 25 per cent of the distribution lies on or below point three of the scale (neutral) and the third quartile (Q3) suggests that 75 per cent of the distribution lies on or below point four of the scale (agree slightly). The standard deviation scores indicate no large deviation between the values of these variables. The frequency distribution results are illustrated by means of a histogram in Figure 1 below. 
Figure 1 Histogram of the frequency distribution results of the role of training in managing organisational change

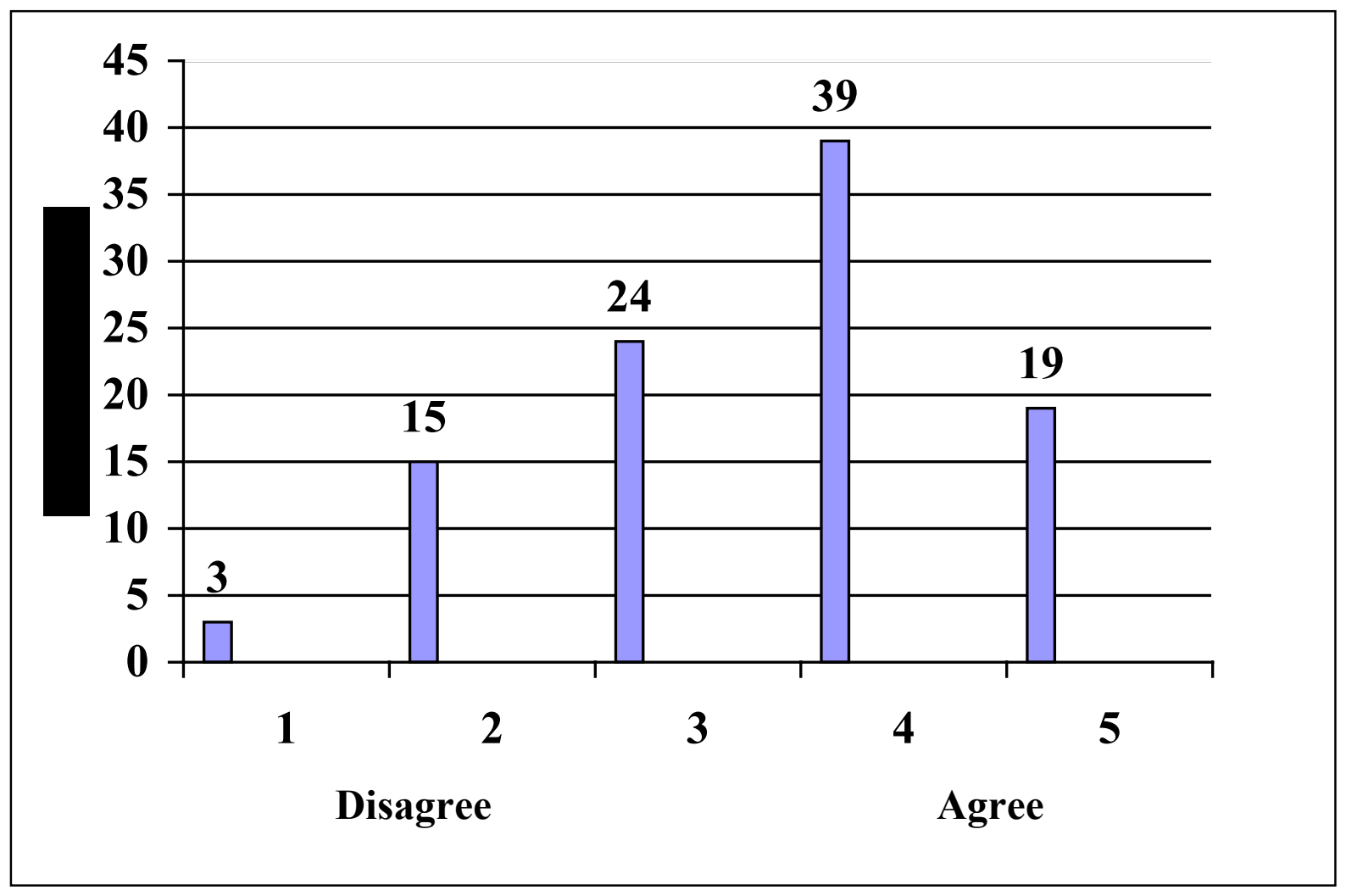

Figure 1 reveals that 18 per cent of respondents ( 3 per cent +15 per cent) disagree with statements regarding the role of training in managing organisational change. Twenty-four percent of the respondents neither agree nor disagree with the variables in this part of the questionnaire. The majority of respondents ( 58 per cent) indicate agreement with the aspects regarding the role of training in managing organisational change (39 per cent +19 per cent). It can be deduced that most of the researched organisations do implement the aspects mentioned and therefore use training as a mechanism to bring about change in the organisation. The distribution can be regarded as negatively skewed and is leptokurtic.

\subsection{ANOVA}

To establish the relationships between the independent and dependent variables, various analyses of variance procedures are conducted. Table 5 highlights the relationship (differences) between the classification data and training variables. Analysis of variance conducted, revealed relationships (differences) with only three of the classification data variables: number of employees (small organisations <100-199 employees; medium size organisations 200-499 employees and large organisations 500-1000+ employees), existence of a 
training department (yes or no) and type of environment (static, moderate changes and dynamic). No other relationships (differences) exist between the classification data and training variables and is, therefore, not significant to report.

Table 5 Analysis of variance results to investigate the relationship between the independent variables (classification data) and the role of training in managing organisational change

\begin{tabular}{|l|c|c|c|c|c||}
\hline Variable & $\begin{array}{c}\text { Sum of } \\
\text { squares }\end{array}$ & $\begin{array}{c}\text { Degrees } \\
\text { of freedom }\end{array}$ & $\begin{array}{c}\text { Mean } \\
\text { square }\end{array}$ & F-test & P-value \\
\hline $\begin{array}{l}\text { Number of } \\
\text { employees }\end{array}$ & 0.92098 & 2 & 0.46049 & 1.24 & 0.2930 \\
\hline $\begin{array}{l}\text { Training } \\
\text { department }\end{array}$ & 12.74529 & 1 & 12.74529 & 34.22 & $0.0000^{* *}$ \\
\hline Environment & 9.05278 & 2 & 4.52639 & 12.15 & $0.0000^{* *}$ \\
\hline Error & 63.68698 & 171 & 0.37244 & & \\
\hline
\end{tabular}

** $\quad$ Significance level of 0.01

The ANOVA results in Table 5 shows that the $\mathrm{F}_{2,171}$ values of 1.24 and the Pvalue of 0.2930 fails to reject the null hypothesis, $\mathrm{H}_{1}$. The calculated values fall outside the rejection region $(\mathrm{p}>0.05)$ and indicate that there is no relationship (difference) between the role of training in managing change and the size of the organisation. The high $\mathrm{F}_{1,171}$ statistic of 34.22 and the P-value of $0.0000(\mathrm{p}<0.01)$ indicates that the calculated values fall within the rejection region and $\mathrm{HO}_{2}$ can therefore be rejected at a significance level of 0.01 . There is a relationship (difference) between an organisation which has a fully developed training department and the role of training in managing organisational change. The null hypothesis, $\mathrm{H}_{3}$, can be rejected, based on the following analysis: $\mathrm{F}_{2}$, 171 value of 12.15 and P-value of 0.0000 . At an alpha level of 0.01 , it appears that there is a highly significant relationship (difference) between the role of training in managing organisational change and the environment in which an organisation operates.

Table 6 shows the ANOVA results which investigate the relationship (difference) between training and organisational change variables. The training variables included in the two factors of Section B of the questionnaire are used as the independent variables. The change variables included in the three factors of Section A of the questionnaire are used as the dependent variables. 
Table 6 Analysis of variance results to investigate the relationship between the independent variables (training) and organisational change

\begin{tabular}{|c|c|c|c|c|c|}
\hline Variable & $\begin{array}{c}\text { Sum of } \\
\text { squares }\end{array}$ & $\begin{array}{c}\text { Degrees } \\
\text { of freedom }\end{array}$ & $\begin{array}{c}\text { Mean } \\
\text { square }\end{array}$ & F-test & P-value \\
\hline $\mathrm{B} 1$ & 23.3714 & 2,179 & 11.6857 & 21.02 & $0.0000^{* *}$ \\
\hline $\mathrm{B} 2$ & 50.5434 & 2,179 & 25.2717 & 57.83 & $0.0000^{* *}$ \\
\hline
\end{tabular}

** Significance level of 0.01

$\mathrm{B} 1=$ The facilitating role of training in the application of organisational change processes

$\mathrm{B} 2=$ The role of training in managing organisational change

The $\mathrm{F}_{2,179}$ value of 57.83 and the P-value of 0.0000 shows that the null hypothesis, $\mathrm{HO}_{4}$, can be rejected $(\mathrm{p}<0.01)$. The facilitating role of training is therefore related to the application of organisational change processes. The $\mathrm{F}_{2}$, 179 value of 21.02 and the $\mathrm{P}$-value of 0.0000 proves that the null hypothesis, $\mathrm{H}_{5}$, can be rejected ( $p<0.01)$. There is a relationship (difference) between the role of training and managing organisational change.

\subsection{Correlation}

The Pearson product-moment correlation coefficient (notation is $r$ ) assesses or measures the degree of association or relationship between two variables and varies between -1 (perfect negative correlation) and +1 (perfect positive correlation). The correlation coefficient indicates the magnitude or strength of the relationship and the direction of the relationship (presence or absence of a minus sign) in a single value. Table 7 highlights the correlation matrix of the variables or factors used in Section A (change) and Section B (training) of the questionnaire.

Table 7 Pearson product-moment correlation coefficients: Section A and $B$ of the questionnaire

\begin{tabular}{|c|c|c|c|c|c|}
\hline Factor & A1 & A2 & A3 & B1 & B2 \\
\hline A1 & 1.0000 & & & & \\
\hline A2 & 0.8620 & 1.0000 & & & \\
\hline $\mathbf{A 3}$ & 0.7840 & 0.8727 & 1.0000 & & \\
\hline B1 & 0.5920 & 0.6867 & 0.7410 & 1.0000 & \\
\hline B2 & 0.5734 & 0.6733 & 0.7258 & 0.8394 & 1.0000 \\
\hline
\end{tabular}


$\mathrm{A} 1=$ Organisational development

$\mathrm{A} 2=$ The learning organisation

$\mathrm{A} 3=$ Transformational leadership

$\mathrm{B} 1=$ The facilitating role of training in the application of change processes

$\mathrm{B} 2=$ The role of training in managing organisational change

In analysing the $r$-values of the correlation matrix in Table 7, the critical value used to interpret these $r$-values, at a significance level of 0.01 , is 0.1720 for a sample size of 182 (effective response rate). The interpretation of Person's $r$ begins by noting that the relationships are positive (as determined by the sign of the calculated values). A positive $r$ describes a positive relationship. All the calculated values of $r$ are greater than the critical value $(r>0.1720)$ which indicates that the relationship between the variables is statistically highly significant. Based on these correlation results, the stated null hypotheses, $\mathrm{H}_{4}$ and $\mathrm{HO}_{5}$, can be rejected at an alpha level of 0.01 . Highly significant relationships exist between the independent variables (training) and the dependent variables (organisational change).

\section{CONCLUSIONS AND RECOMMENDATIONS}

Increased emphasis should be placed on understanding the changing picture of the world in which organisations operate, as this provides the context in which to consider the future of training management. Continuous, rapid learning must become a priority for organisations in order to keep up with new methods, changing trends and advanced technology. The following relationships between the independent variables (classification data), and the role of training in managing organisational change, were identified:

- It appears that the employment size of an organisation has no relationship with the role of training in managing organisational change $\left(\mathrm{H}_{1}\right.$ not rejected). Organisations with different employment sizes do not differ with the regard to the role of training in managing organisational change.

- There is a highly significant relationship between an organisation which has a fully developed training department and the role of training in managing organisational change $\left(\mathrm{HO}_{2}\right.$ rejected). Organisations in which a fully developed training department exist, differ from those organisations in which training is not a fully developed function or department regarding the role of training in managing organisational change.

- The type of environment in which an organisation operates is related to the role of training in managing organisational change $\left(\mathrm{HO}_{3}\right.$ rejected). Organisations operating in a dynamic environment differ from 
organisations operating in a moderate or static environment regarding the role of training in managing organisational change.

The following conclusions can be drawn from the relationship between training and change variables:

- There is a highly significant relationship between the role of training and managing organisational change $\left(\mathrm{HO}_{4}\right.$ rejected). Training could therefore be used to manage change in an organisation.

- There is a highly significant relationship between the facilitating role of training and the application of organisational change processes $\left(\mathrm{HO}_{5}\right.$ rejected). The implementation of change processes in the organisation could be facilitated by training.

In order to meet the new requirements of the marketplace, training should undergo some kind of transformation. A focussed approach (as opposed to a fragmented and formalised approach) should view training as: a continuous learning process, a competitive weapon, self-selected and non-directive and a means to link organisational strategy and individual goals. It is important to realise that many training experiences lack positive results because of unrealistic expectations. Training cannot alter personalities or habits overnight. It is important for management to have an overall view of training so as to effect change in employee behaviour and to realise that some kind of learning must occur if change is to take place.

The following could serve as general guidelines and recommendations for implementing training perspectives as a tool to manage organisational change (based on the training perspectives empirically tested):

- The training process in the organisation should be related to the context of the external environment in which the organisation operates.

- It should be realised that training for change is vital for the long-term survival of the organisation.

- Training programmes should enhance the capacity of people to cope with change.

- Organisations should upgrade managerial capabilities in situations of rapid change.

- Training programmes should respond to shifts in strategic actions of the organisation.

- Training initiatives should be linked to the mission of the organisation.

- Training people for change, prior to it taking place, could assist in understanding why change is necessary. 
- Management should not only view training as a functional area, but one which possesses the necessary capabilities to help transform the organisation.

- Training should assist people to become change agents in the organisation.

- Management should realise there is a need for a new approach to training which will promote continuous adaptation in the organisation.

The following extract by Harri-Augstein and Webb (1995: 146) is appropriate with which to conclude this article:

"Many attempts ... have failed, because intentions to change are organised around a theory or idea ... a fundamental change in the role of training involves a shift in attitudes from a traditional view of training towards the more radical view of enabling learning ... this shift involves truly recognising the implications of a transformation ..."

\section{REFERENCES}

1 ADONISI, M. (1991) "Training as a corporate strategy", IPM Journal, 10(1): 27-30.

2 AMERICAN SOCIETY FOR TRAINING AND DEVELOPMENT. (2000) "Employee orientation and training - Training trends", http://www.bsad.uvm.edu/hrm/training/trendsarticle Downloaded: 200205-22.

3 BAIRD, L.S., SCHNEIER, C.E., \& LAIRD, D. (1983) The Training and Development Source Book, Human Resource Development Press: Massachusetts.

4 BERGGREN, R. (2000) "Corporate training: lifelong learning in a global marketplace", http://www.eist.uib.no/eucen-conference Downloaded: 2002-05-22.

5 BLUNT, P., \& JONES, M.L. (1992) Managing Organisations in Africa, Walter de Gruyter: Berlin.

6 BOWDITCH, J.L. \& BUONO, A.F. (1994) A Primer on Organizational Behaviour, John Wiley \& Sons, Inc: New York.

7 BOWIN, R.B., \& HARVEY, D. (2001) Human Resource Management, Prentice-Hall: New Jersey.

8 BOWMAN, C., \& JARRETT, M.G. (1996) Management in Practice: A Framework for Managing Organizational Change, ButterworthHeinemann: Oxford.

9 BRILL, P.L., \& Worth, R. (1997) The Four Levers of Corporate Change, Amacom: New York. 
10 BUCKLEY, R., \& CAPLE, J. (1992) The Theory and Practice of Training, Kogan Page: London.

11 BUDD, M.J. (1996) "Hrd/organization alignment model", http://www. opm.gov/hrd/lead/pubs. Downloaded: 2002-05-22.

12 BURNES, B. (1996) Managing Change: A Strategic Approach to Organisational Dynamics, Pitman Publishing: London.

13 CARROLL, C. (1998) "Training guru predicts trends", http://www. computingsa.co.za. Downloaded: 2002-05-22.

14 CORPORATE TRAINING CONSULTANTS (2000) Establishing and aligning the training function", http://www.enhancedtraining. com/establish-training. Downloaded: 2002-5-22.

15 DAVIS, J.R., \& DAVIS, A.B. (2001) Effective Training Strategies, Berrett-Koehler Publishers: San Francisco.

16 DAWSON, S. (1992) Analysing Organisations, The MacMillan Press, Ltd: Hampshire.

17 DAWSON, P. (1994) Organisational Change: A Processual Approach, Paul Chapman Publishing, Ltd: London.

18 EAGAR, M. (1996) "Workplace learning as a tool for transformation", People Dynamics, 14(11): 60-64.

19 ERASMUS, B.J., \& VAN DYK, P.S. (1996) Training Management: A Practical Approach, International Thompson Publishing: Johannesburg.

20 GERBER, P.D., NEL, P.S., VAN DYK, P.S., HAASBROEK, G.D., SCHULTZ, H.B., SONO, T.J., \& WERNER, A. (2001) Human Resources Management, Oxford University Press: Cape Town.

21 GOMEZ-MEJIA, L.R., BALKIN, D.B., \& CARDY, R.L. (2001) Managing Human Resources, Prentice-Hall: New Jersey.

22 HAMMER, M. \& CHAMPY, J. (1993) Re-Engineering the Corporation: A Manifesto for Business Revolution, New York: Harper.

23 HARDINGHAM, A. (1997) Designing Training, Institute for Personnel Development: London .

24 HELLRIEGEL, D. \& SLOCUM, J.W. (1996) Management, SouthWestern Publishing Company: Ohio.

25 HENDRY, J., JOHNSON, G. \& NEWTON, J. (1994) Strategic Thinking: Leadership and the Management of Change, John Wiley \& Sons: Chichester.

26 HERSEY, P., BLANCHARD, K.H. \& JOHNSON, D.E. (1996) Management of Organizational Behaviour, Prentice-Hall, Inc: New Jersey

27 HONOLD, L. (2000) Developing Employees who Love to Learn. DaviesBlack Publishing: California.

28 HUMAN, L. (1991) Educating and Developing managers for a Changing South Africa, Juta \& Company, Ltd: Cape Town.

29 HARRI-AUGSTEIN, S., \& WEBB, I.M. (1995) Learning to Change, McGraw-Hill Book Company: London. 
30 JARVIS, C. (2002) "Trends in the 90's - Related movements", http://www.solbrunel.ac.uk/Jarvis/bola/training/trends. Downloaded: 2002-05-22.

31 JOYCE, P., \& WOODS, A. (1996) Essential Strategic Management: From Modernism to Pragmatism, Butterworth-Heinemann: Oxford.

32 KANTER, R.M., STEIN, B.A., \& JICK, T.D. (1992) The Challenge of Organizational Change, The Free Press: New York.

33 KEMPL, S.F., \& PACE, R.W. (2001) Training Across Multiple Locations, Berrett-Koehler Publishers: San Francisco.

34 LARWOOD, L. (1984) Organizational Behaviour and Management, Kent Publishing Company: Boston.

35 LIPPITT, M. (1997) "Trends in corporate training", http://www.jalmc.org/. Downloaded: 2002-05-22.

36 MANNING, T. (1996) "Managing minds - Something different", Productivity South Africa, 22(4): 7-10.

37 MASIE, E. (2002) "Trends and barriers in the future of corporate training", http://www.lotus.com/news/n../public, Downloaded: 2002-0522.

38 NICKOLS, F. (2000) "Training - A strategic view", http//www.home.att. net/nickels/strategic_view. Downloaded: 2002-05-22.

39 OGBONNA, J. (2002) "The role of training in the management of change related to information technology", http://spica.soi.city.ac.uk/project, Downloaded: 2002-05-20.

40 OPEN LEARNING TECHNOLOGY CORPORATION (1995) "Open learning and general trends in education and training", http://www/ educationau.edu.au/archives/olsat, Downloaded: 2002-05-22.

41 OSBALDESTON, M., \& BARHAM, K. (1992) "Using management development for competitive advantage", Long Range Planning, 25(6): 18-24.

42 ROBBINS, S.P. (1996) Organizational Behavior, Prentice-Hall, Inc: New Jersey.

43 SETARO, J.L. (2002) "Trends in training", http://www.thinq.com/pages/ new wp trendsintraining, Downloaded: 2002-05-22.

44 SMIT, P.J. \& CRONJE, G.J.DE J. (1997) Management Principles, Juta: Kenwyn.

45 STAMELMAN, M. (2000) "S.A. corporations must become players in the world-class global village", People Dynamics, 18 (5): 32-34.

46 TEKE, M. (1997) "Empowering the South African worker", People Dynamics, 15(10): 23-31.

47 TOBIN, D.R. (1993) Re-educating the Corporation, Oliver Wight Publications, Inc: Essex Junction.

48 THOMPSON, R. (1995) Managing People, Butterworth-Heineman: Oxford. 
49 THOMPSON, R., \& MABEY, C. (1994) Developing Human Resources, Butterworth: Oxford.

50 VAN DYK, P.S., NEL, P.S., LOEDOLFF, P VAN Z., \& HAASBROEK, G.D. (1997) Training Management: A Multi Disciplinary Approach to Human Resources Development in South Africa, International Thompson Publishing: Johannesburg. 